\title{
Effect of different doses of diclofenac sodium on the hippocampus development during the first trimester of pregnancy
}

\author{
Ebru Elibola*, Süleyman Kaplan ${ }^{a}$, Aysın Pınar Türkmen ${ }^{a}$, Abdurrahman Aksoy ${ }^{b}$, Kübra Yurt ${ }^{\mathrm{a}}$, Gamze Altun ${ }^{\mathrm{a}}$, \\ Mehmet Emin Öngera ${ }^{a}$ Berrin Zuhal Altunkaynak ${ }^{a}$
}

${ }^{a}$ Department of Histology and Embryology, Faculty of Medicine, Ondokuz Mayls University, Samsun, Turkey

${ }^{b}$ Department of Pharmacology, Faculty of Veterinary Medicine, Ondokuz, Mayı University, Samsun, Turkey

\section{ARTICLE INFO}

\section{* Correspondence to:}

Ebru Elibol

Department of Histology and Embryology, Faculty of Medicine,

Ondokuz Mayıs University, Samsun, Turkey e-mail: ebru_ayranci@hotmail.com

\section{Keywords:}

Diclofenac sodium

Hippocampus

Pregnancy

Rats

Stereology

\section{ABSTRACT}

In the present study it was aimed to investigate the toxic effects of different doses of diclofenac sodium on the rat hippocampus that is exposed during first trimester of prenatal period using stereological and histopathological techniques. For this aim, 30 male offspring Wistar albino rats were used. The subjects were divided into five main groups. These are pure control, saline, low dose $(3.9 \mathrm{mg} / \mathrm{kg})$, medium dose $(9 \mathrm{mg} / \mathrm{kg})$ and high dose $(18 \mathrm{mg} / \mathrm{kg})$. These doses are given during the first trimester (0-7 days) of pregnancy. After delivery; on the $8^{\text {th }}$ day of the postnatal life, all animals were euthanized with an overdose of aesthetic. Then, the brain tissue samples were analysed by histological and stereological techniques. In the diclofenac sodium administered groups it was observed a significant decrease in terms of the average neuron number in the CA1, CA2 and CA3 regions and whole hippocampus compared to the pure control and the saline groups. When it was compared to CA regions of hippocampus among themselves, there was a significant dose dependent effect in terms of the average neuron number in the CA1 and CA3 regions but not in CA2 region. Light microscopic investigation of the drug administered groups indicated significant decrease in the number of healthy neurons. Additionally in the high dose group, it was identified more necrotic neurons compared to the other groups. It was found that diclofenac sodium causes decreasing the number of the neurons in the CA1, CA2, and CA3 regions and whole hippocampus. Although dose-dependent effects of diclofenac sodium on the number of neurons in CA1 and CA3 regions were seen, this effect was not seen in CA2 region.

J. Exp.Clin.Med., 2014; 31:136 